\title{
Impact of Urban Open and Multi-Functional Spaces on the Quality of Leisure Time of Citizens Based on Social Capital
}

\author{
Ghazal Lotfi Zadeh \\ Master of Architecture, Department of Architecture ,Islamic Azad University - Tehran North Branch, Iran \\ Jamal-e-Din Mahdi Nejad
}

Assistant Professor in Department of Architecture, Shahid Rajaee Teacher Training University, Tehran, Iran

\section{Doi:10.5901/mjss.2016.v7n4s1p143}

\begin{abstract}
With the emergence of new social, economic and cultural conditions in the new era, leisure is raised as one of the important issues in life and the quality of spending it is also more significant. In modern times, the need for spending leisure times includes the important needs of the people. In general, leisure refers to a time when a person does all matters related to the work, sleep and other basic needs and is free from such constraints. Showing the importance of leisure and close relation of leisure actively in urban areas, the present paper examines the status of leisure time in people's life and tries to determine the role of urban open spaces for leisure time and examines the urban open spaces and the problems associated with it and finally, it provides recommendations for an urban space. In this research, qualitative research methods (descriptive - analytical) is used and data is collected through evidences and library documents, computer network information.
\end{abstract}

Keywords: Leisure time, urban open space, play space, multi-functional set design.

\section{Introduction}

High density of buildings in major cities, scarcity and high time price are barriers to the creation of sport, recreation and tourism spaces to meet the residents' needs. So, the lands on city margins and even suburban areas with good weather are considered as an alternative method. Lack of an administrative power in Iran in this field is one of the major obstacles to deal with it. This means that municipalities within the legal limits of the city bind themselves to planning and beyond it, they see it out of the scope of their responsibility. Crowds on holidays in parks and recreation areas within the city as well as the withdrawal of hundreds of thousands of people to the suburbs and sheltering in the lap of nature during the weekends are manifestations of the lack of city recreational facilities as well as tiresome of concerns of urban life which show the necessity to pay attention to urban recreational facilities.

In modern times, the need for spending leisure times includes the main needs of the people. In general, leisure time refers to a time when a person does all matters related to the work, sleep and other basic needs and is free from such constraints. Leisure activities refer to any kind of entertainment can be done at this time that can includes a variety of sporting, artistic, scientific activities, and so on. Doing such activities need its proper spaces and attention to urban centers and prediction of areas suitable for spending leisure time in the city seems necessary. Thus, recognition of appropriate spaces for leisure time and promoting quality of these spaces can be effective in solving the problems of many cities. Cities are composed of different spaces and each of them are formed for support and facilitation of individual and social activities and creating meanings that citizens need. Given that any activity requires a space with special characteristics or right behavioral bases, in the absence of suitable space, the quality of type of activities will be in trouble and ultimately the existence of city will be faced with the disorder from various social, cultural and identity aspects. So, the study of human needs, meeting and improving the quality of spaces required for citizens' activities is a significant issue for designers and urban planners. Iran cities have similar features physically, in many of them, ancient structure is vanished with the city's development and greater use of cars, and the new city structure with an unbalanced growth has been developed in various domains. On the other hand, imbalances in social aspects and city centers cause social problems that one of them is the lack of proper space for leisure, especially for young people. Reviewing social spaces and recommending strategies to promote the quality of social spaces in the urban context can reduce problems. This study reviews the social spaces of cities and raises tips for improving their quality in spending leisure time. 


\section{Necessity and Importance of Subject}

Individualism, lack of security to participate in the community, loss of local context and the interface that contributes to solidarity among residents all reduce social interactions and fade it at the local level. Since, after home, neighborhood is where people spend most of his time and commutes in it, is an important element in the formation of social interaction among its residents. Since, in past neighborhoods played a major widespread role in shaping social interactions, therefore it is tried to consider the needs of current modern society and its users due to values in the spaces, design and construct a sociable and participatory space that in addition to a place for social exchanges, induce a sense of place and a sense of belonging besides security to person.

\section{Research Method}

In this research, the following sources are used to collect information:

1. Using Internet Universal Network and reputable websites

2. Desk studies and research done in this area

\section{Leisure Time and Its Goals}

Leisure activities is of such importance today that is referred to as a mirror of society culture, this means that how to spend leisure of the people of a community represents to a great extent the cultural characteristics of that community. With the increasing importance of leisure, Marks and Rekardo values about the importance of job and productive role in shaping the personality and identity of the man is faded (Rafatjah et al., 2010). In past, leisure was more or less associated with unemployment and was considered as mother of all evils. Today, leisure is the basis of a new ethics based on good fortune. Someone who does not use his spare time or cannot benefit from it, is not considered as a perfect human but a laggard between animals and humans.

Leisure is the most pleasant time for man. Part of his life that is his own. Hours regardless of daily work and suffering of days that he spends it as he wants, he chooses it and if a factor out of it doesn't interfere, he spends it willingly. These moments for scholars are moments of contemplation, for the artists is a time for creating and for ignorant and artless ones are the most boring time. That is why the time for some is fruitful and exciting and for some is the most evil. A great time that its one end is fertilizing lives and it's another end is wasting the sweet moments. Leisure time are closest to the spiritual life and culture. Leisure time is a time when a person has to rest for refreshment, has fun to overcome illness and does activities for the development of his body and soul capacities. Heywood (2005: 18) categorizes the leisure concepts in some classes:

- leisure time as a residue of time: Leisure time is considered as non-executive times i.e. the optional times remaining after the working time and doing the matters related to livelihood and one can do his favorite job with relative freedom.

- Leisure time as activity: Here, the attention is paid from person to nature of activities such as sports, watching TV, art, dance, entertainments, vacation and drinking beverages. Most of these activities are described as breezy and pleasant and are called entertainment.

- Leisure from operational view: From this perspective, leisure activities consist of beneficial acts for people and specifically for community; so, in this sense leisure time is a tool for achieving the desired and socially accepted goals.

- Leisure from the perspective of freedom of action: Human has leisure time when is free from the commitments which encompassed other life layers; leisure time is associated with freedom and possibility that person be himself and expresses himself. Historically, this kind of attitude to leisure time is related to "premium" group, which are prosperous enough in terms of financial independence and time that that can under ideal conditions, provide a way of life that is based on leisure.

Different cultures provide different views of the leisure. In capitalism view, leisure activities need to invest time and money. Therefore, the involvement of the poor in these activities seems impossible. Some also work a lot to meet the leisure expenses and know it as a necessity for reaching higher positions. Reviewing various views shows leisure activities can include various kind of activities. Such activities usually adapt to individual taste and interest, and may not have any financial benefit to the individual. When addressing these activities, person tries to accomplish goals such as relaxation, improving physical or intellectual condition, showcasing individual skills, build relationships with other people 
and generally readiness to continue work and life (Reza Zadeh, 2003). Leisure in sense of free time does not seem right because if one has a lot of free time, but has no program to spend it is not spending leisure time, but idleness, which follows social and individual harms. Therefore, leisure activities can be divided into active and passive ones. It seems that the strictest sense of leisure is doing the preferred activities freely. However, the desired activity can be active or inactive. For example, when doing sport or playing music, active interaction takes place, while watching football or listening to music through media is such that leisure activities is done passively. There must be balance and coordination between the two types of activities to meet individual and community health. But today in the city, a major part of leisure activities, especially for the youth is passive; so that movement of citizens is greatly reduced and they prefer to spend their leisure time in stillness and this inactivity leads to depression and boresome. These activities are associated with mental and physical comfort. It failed to meet the spiritual needs of man, so leisure is examined from another concept, meaning that leisure can be considered a mode of perception. The idea was founded by Aristotle and has continued to day. In this view, leisure is introduced as a form of thought and personal progress and it is necessary as the greatest assets for person development and makes him to leave daily activities and pay attention to what is really important. This view which has human orientations at the same time improves the human relationship with God and tendency towards him. Summarizing the comments on leisure, we can say spending leisure time is done with three aims "providing a platform for personal and social development" and "the provision of leisure" and "comfort".

\section{General Definition of Social Capital}

Social capital is defined as a capacity (Social essence) that facilitates coordination and cooperation in the community and group. In fact, social capital can be considered as a complex concept that has three dimensions: content, structure, and function which social structure is the social communication network, and its content is trust and social norms and its function is social interaction.

\section{Concepts of Social Capital}

The concept of social capital has entered into social and economic sciences since 1960s. Social capital doesn't exist within an individual or a social organization but in the communication between people (Ghasemi et al., 2006 and Sa'adat, 2006). Today, scientists and theorists such as James Coleman (1966), Glenn Lowry (1970), Ben Pratt (1980), Williamson (1981), Baker (1983) and Francis Fukuyama (1990) and so on provided numerous definitions of capital social. For example, Pierre Bourdieu identified three types of capital including social, economic and cultural capitals. He knew social capital as a form of capital which focuses on communication and participation of the members of an organization and associated with cultural capital, can be a means to achieve economic capital.

As you can see, this latter view in the context of social capital, is a mere a instrumental view. In other words, from the perspective of Bourdieu, if social capital cannot result in economic growth, it will not work. But James Coleman, unlike Bourdieu in defining social capital, used its role and function and provided an operational definition (not merely intellectual and theoretical) of the social capital. Accordingly, social capital is the value of that aspect of social structure that serves members as a resource to achieve their goals and interests. Many theories have been expressed in the context of social capital, including the theory of weak ties, structural gap theory and the theory of social resources (Lynch, 2012, 22). Fukuyama considers the essential element of social capital as informal norms or values that help to create and enhance group collaboration (Fukuyama, 2000, 11). Social capital can be defined as the ability of people to work together to achieve common goals in groups and organizations (Coleman, 1988). According to Paxton, social capital is the mental or sensory links among people in the community. (Firoozabadi and Imani, 2006, 200) Many organizations used different methods to measure social capital and its social, economic and political consequences. (Hemmati, 2007, 7) The organization presented four major indicators of social capital. These include: community participation, social trust, social networks and social belonging (Ghiasvand, 2009, 21) 
Table 1: Definition, objective and analysis unit of social capital from the perspective of experts (Nateghpour and Firoozabadi, 2006, 23)

\begin{tabular}{|l|l|l|l|}
\hline Experts & Definition of social capital & Objective & Analysis Unit \\
\hline Bourdieu & $\begin{array}{l}\text { Resources that can provide access to group } \\
\text { benefits. }\end{array}$ & Maintaining economic capital & $\begin{array}{l}\text { People in the class } \\
\text { competition }\end{array}$ \\
\hline Coleman & $\begin{array}{l}\text { Aspects of social construction that actors use them } \\
\text { as resources for their own benefit. }\end{array}$ & Maintaining human capital & $\begin{array}{l}\text { People in family and in } \\
\text { social networks }\end{array}$ \\
\hline $\begin{array}{l}\text { Putnam and } \\
\text { Fukuyama }\end{array}$ & $\begin{array}{l}\text { Beliefs, norms and networks that facilitate } \\
\text { cooperation for mutual benefits. }\end{array}$ & $\begin{array}{l}\text { Maintaining economy and effective } \\
\text { and efficient democracy }\end{array}$ & Country regions \\
\hline Offe and Fuchs & $\begin{array}{l}\text { Knowledge and attention to political and social } \\
\text { affairs, belief and participation }\end{array}$ & Economic efficiency & People \\
\hline
\end{tabular}

Finally, we can say that social capital is as follows: (Alizadeh et al., 2014)

1. Generalized norms to mutual assistance among members of the local community (values / beliefs)

2. Social networks that promote cooperation and closeness among people (public institutions)

3. Results of the close cooperation of the people by harmonized purpose / purposes (cooperation norms)

4. The three have strong dependence and interaction with physical, human and economic capital which help accelerating economic, cultural and information development and the growth and development of community and create a sense of cooperation and partnership among the community members (Mousavi et al., 2012, 112).

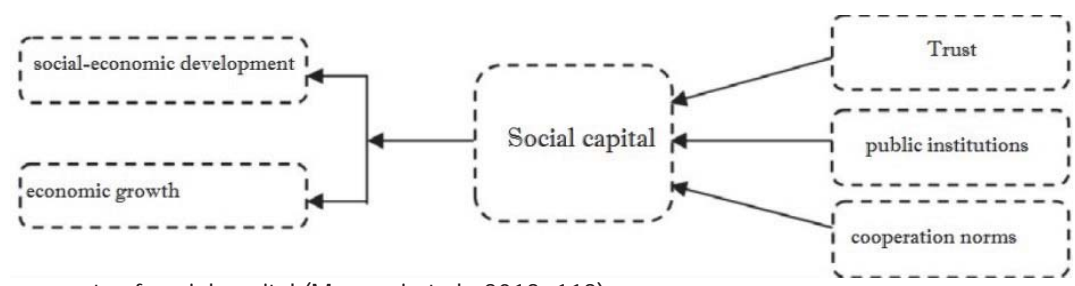

Figure 1: Components of social capital (Mousavi et al., 2012, 112)

\section{Social Capital and Security}

Social capital is the driving force and the potential for interaction between police and citizens act. Social capital acts as the driving force and the potential for interaction between police and citizens. Social capital can be divided into two categories: anterior and posterior that anterior social capital leads to narrow security and posterior social capital leads to the realization of a broad security. Posterior social capital is an evidence of the benefits, opportunities and possibilities that the group have benefited from it without effort, based on the functions of the former members. Posterior social capital requires efforts of members of group to establish the optimal interaction to receive necessary information and facilities. In fact, posterior social capital is group inheritance which inherited to new members, but posterior social capital is provided through the actions and relations of present people (Navidnia, 2009).

\section{Sociability}

Collective life is an opportunity to get away from everyday stresses, spending leisure time, social interactions and meeting different people and groups and a context for presence and freedom of expression in the space (Sennette, 1974: 215). Collective life in public open spaces lies in promoting social interaction (Whyte, 1980), attracting different people and groups, social security and thus encouraging increased tolerance of different groups in space, more sociability (Marcus \& Francis, 1998) and creating an active and lively space.

\section{Urban Open Space and Increased Interaction}

Social interaction means creating a relationship between two or more people which leads to a reaction among them and this type of reaction is known to both sides (Behzadfar and Tahmasebi, 2013). Social interaction and communication can 
be a physical issue, a look, a conversation and communication between people which in turn requires defining events and activities and thus imprinting people in space and their membership in social groups and networks (Daneshpur and Charkhian 2007, 22).

Urban space is as a physical structure for social interaction where access to it is possible for members of civil society. Public open space everyday has changed unfamiliar to familiar people and provides a place for social and group relations. Square and streets as the city public open spaces are spaces which importance, after the Industrial Revolution, is established for researchers. These spaces are physical symbol of the social - political ideas of social activists. Urban space is a social concept in which all segments of society can equally use it and is theater play scene for citizens who attending in it, they put on a mask and they do social interaction in an incorporation of social species and that is why urban space itself is a form of social capital (Madanipur, 2003). Open spaces help people to create a sense of trust and confidence and increase solidarity and a sense of belonging in public. In fact, these spaces are more than just a place solely for the passive presence (Pakzad, 2010). In a study on more than a thousand public spaces in various countries, it has been shown that four key factors are more important in assessing the qualitative appropriateness of urban public spaces that are: access, coherence, comfort and landscape, uses and activities and sociability.

Public spaces, with the potential capacity in the first phase, provide this equal opportunity to generate and establish social (albeit fragile) actions to all citizens. In the next step, after the "conclusion" of social interaction, differences in social, economic and cultural levels which create varied behavioral patterns are a contexts for development of coherent and stable social relationships (Qanbaran, 2004, 178). Lennard considers two factors of body and prediction and creating social events as factors effective in the social presence and interaction of individuals that is effective in promoting a sense of place (Lennard, 2007). Man needs to love and being in a community requires a physical settlement and urban public spaces have the maximum capacity in this regard (Ghanbaran and Jafari, 2014). Relaxed atmosphere, natural factors, space privacy and controlling vehicles are effective since they provide human need for rest (Whyte, 1980).

\section{Urban Open Spaces and Spending Leisure Time}

Like any individual and social activities, leisure needs a physical environment which is able to meet its mental and activity needs. Although, different spaces for sport, recreation and function in cities are created for spending leisure in different ages, but open and high quality urban spaces as a behavioral base, can meet many needs of leisure time. Behavioral base is a small social unit from integration of a sustainable activity and a place, so that in a regular process can meet the essential functions of the environment. Behavioral base is like a living system that has the following characteristics (Lang, 2002)

A. Repeatable activity: In behavioral base, behaviors occur parallel to each other, behaviors like obvious emotional behavior and changing things. The combination of these behaviors which constitute a consistent pattern is placed in a particular field, which is the same physical environment. In urban open spaces it occurs as behavioral base for leisure, activities such as thinking, relaxation, major motor activities such as recreation, sports, game, interaction of people, and so on that these activities are usually almost identical and repeatable and specific to this base. In other words, these activities are considered as stable pattern in the physical environment.

B. Certain design of environment or the physical environment: Each behavioral base has an internal structure. This structure can be synchronized with the physical environment internal system. Different individuals or groups due to various roles, occupy various parts of the behavioral base. Many of the behavioral base structures are formed based on who controls the behavior. In urban open spaces that are used by people in their leisure time, people are placed in different parts of the spaces by age, gender, interests and so on, and somehow affect the system in the base. For example, the placement of sitting space next to kids' play space increases parental control over children current pattern or closeness of the platforms and cozy spaces to each other creates interaction among people and the intensification of this behavior.

C. Homology: In behavioral base, there is a consistent relationship between the two behavioral elements which is called homology. Homology means that a place - behavior will not be formed without linking the physical environment and human behavior. In fact urban spaces should be in a way that are appropriate to different age and sex groups and their needs and behaviors and homology can be created among the physical environment and behavior.

D. Period of time: Each behavioral base can be consisted of several bases that in different times, different behaviors are done in them. In urban open spaces, most used time is summer and leisure time of people, 
especially the youth and adolescents. In addition to the above characteristics, behavioral base with a program and a controlling factor, enables one to achieve satisfaction and the satisfactions are different for different people. A behavioral base or place can reach one to self-fulfillment and the place can also provide the basic needs of another person.

\section{Conclusion}

Experts in social interactions emphasize the role of public spaces in creating social interactions and believe that more than any other factor, the presence of other people in space attracts people to it. On the other hand, social aspects and current activities in space, along with formal aspects and visual beauty that the human experience of movement within the space is perceived by him, is considered as a contributing factor in the formation of interactions among people. Also, partnership and cooperation is a factor for promoting social interaction. Public space promotes social interaction among residents and thus social capital can improve the quality of subjective life of people.

Study of urban open spaces for leisure time in Iran show that most cities are not proper in the provision of these spaces in terms of quantity and quality. This means that the areas in most cases are not in accordance with the needs, interests and characteristics of users. This causes lack of coordination and belonging between the individual and the environment and lack of correct and appropriate use by people especially the youth. In total, the main problems of urban open spaces can be considered on two following main aspects:

a) Quantitative problems of urban open spaces: Lack or absence of proper urban open spaces and not being planned in most towns for reasons such as age and high density of context are the main problems of urban spaces in Iran. Lack of coordination of urban open spaces with the current situation or land use change of open space to other uses has diminished the role of these spaces. In some cases, the lack of affordable access to open spaces in terms of location, dispersion and distance from urban centers cause lack of interest of the citizens to these spaces. In fact, all the problems cause by the mismatch between urban planning and the current needs of the city.

b) Qualitative problems in urban open spaces: qualitative problems and ravages of urban open spaces in Iran can be categorized in the following fields:

- Poor function of present urban open spaces: inability of open spaces in communicating and adapting with users because of the physical, psychological and social features of users and the time to use these spaces are created in their design.

- Lack of attention to geographic, cultural, social and economic condition of city: incompatibility of some urban open spaces with climatic conditions such as cold, wind and sun, as well as lack of attention to social and cultural issues that result in lack of space anonymousness and lack of attachment of people to these spaces.

\section{Recommendations}

Due to the problems expressed for urban open spaces, the following suggestions are provided for improving the quality of spending leisure time:

- Planning, designing and creating urban open spaces in terms of number, area and position according to the population in different areas of cities.

- Considering urban open spaces as one of structural elements of urban design so that in the design of city, other urban elements are formed based on urban open spaces. Therefore, dedicating waste spaces to urban areas should be avoided.

- Maintaining and improving traditional open spaces to maintain urban identity and their coordination with modern needs, so that while solving urban development problems, urban cultural and social sustainability of city can be considered.

- Improving the quality of urban open spaces based on design criteria and physical and psychological needs of people, especially young people, also noting the time for using these spaces that are mostly used in the summer and in leisure time.

- Designing urban open spaces based on climatic characteristics of cities and creating a climate of comfort in these spaces for users.

- Considering cultural and social conditions of city in creating urban open spaces to establish a sense of 
belonging and the development of psychological security, especially for women and children.

- Considering the creation of proper and urban open spaces with identity in terms of closeness, proper form, context and materials, proper elements and furniture.

\section{References}

Navidnia, Manije, 2009. Police, security, and social capital, Tehran: Journal of Strategic Studies, year 12, No. 2.

Fukuyama, Francis, 2000. The end of regulation, social capital and its maintenance, translated by GHolam Abbas Tavassoli, Tehran, Jame Iranian Press.

Firoozabadi, Ahmad and Hossein Imani, 2006, Social Capital and Development, Journal of Social Welfare, No. 23, pp. 197-224.

Hemmati, Reza, 2007, social capital, psychological challenges and measuring tools, Conference on Social Capital and Economic Development, Higher Education and Research Institute for the Management and Planning Organization.

Ghiasvand, Elham, 2009, impact of social capital on quality of life for residents of urban neighborhoods, Journal of Consulting Engineer, No. 45.

Lynch, Kevin, 2012. Theory of city shape, translated by Seyyed Hossein Bahreini, Tehran University Press, Tehran.

Nateghpour, Mohammad Javad and Ahmad Firoozabadi, 2006, the formation of social capital and factors affecting it, Journal of social sciences, No. 28, pp. 160-190.

Saadat, Rahman, 2006, estimating the level and distribution of social capital of provinces, Journal of Social Welfare, No. 23, pp. 173197.

Ghasemi, Vahid and Reza Esmaeili and Kamran Rabiei, 2006, classification of social capital in the cities of Isfahan, Journal of Social Welfare, No. 23, pp. 225, 251.

Madanipour, Ali, 2008, public and private spaces of the city, translated by Farshad Nourian, urban processing and planning Co., Tehran.

Pakzad, Jahanshah, 2010, the process of thought in urban planning, Vol. III, Department of Housing and Urban Development, Tehran.

Ghanbaran, Abdul-Hamid, Jafari Marzieh, 2014, Factors affecting promotion of social interaction among residents of a residential neighborhood (Case Study: Darake Neighborhood - Tehran), Scientific - Research Journal of Scientific Society of Iranian Architecture and Urbanism, No. 7.

Mousavi Mir Najaf et al., 2012, the role of social capital in the modernization and improvement of worn out contexts, case study: Dardasht city, Urban and Regional Studies and Research, No. 15, 122-105.

Alizadeh, Houshmand et al., 2014, Study of social capital in three space of Sanandaj, informal settlements, central contexts and planned contexts, Journal of Art University, Architecture and Urban Planning Journal, No. 13.

Heywood, L, et al., 2005, Leisure, Translator: Mohammad Ehsani, Tehran: Bamdad Ketab.

Rafatjah, Maryam, Marjan Rashvand and Maryam Shahidi Zandi, 2010, sociological explanation of young girls' leisure activities with an emphasis on its pathological factors.

Daneshpur, Seyyed Abdul-Hadi and Maryam Charkhchian, 2007, public spaces and factors affecting communal life, journal of Baq Nazar, 4 (7): 19- 28.

Behzadfar, Mostafa, Arsalan Tahmasebi, 2013, identification and evaluation of the factors affecting social interactions of consolidation and development of social relations in the urban streets: case study: Sanandaj, Baq Nazar journal, No. 25, Vol. 10, 17- 28.

Lang, John; creation of architectural theory: the role of behavioral sciences in environmental design, translated by Alireza Einifar. Tehran: Tehran University Press, 2002

Reza Zadeh, Raziye, Yazdanpanah, Mahnoush, 2013, activity - behavioral patterns in leisure use planning, Journal, 16 municipalities, No. 49 , pp. 12

Lennard \& Lennard (1984). Public Life in Urban Places, Godlier, Southampton.

Ghanbaran A. H. (2004). Iranischer Basar im Wandel, Stuttgart.

Whyte W (1980). Social Life of Small Urban Space, Conservation Foundation.

Coleman J S, 1988, social capital in the creation of human capital, Am. J. social, 94: 95. 121.

Sennette, R. (one thousand nine hundred and seventy-four). The Fall of Public Man. New York: WW Norton \& company.

Marcus, CC, \& Francis, C. (1 998). People places: Design guide lines for urban open space. New York: NY: Van Nostrand Reinhold. 